\title{
28 Research Square \\ Cost-effectiveness analysis for HbA1c test intervals to screen patients with type 2 diabetes based on risk stratification.
}

Sachiko Ohde ( $\nabla$ saohde@luke.ac.jp )

St. Luke's International University https://orcid.org/0000-0001-9137-0047

Kensuke Moriwaki

Ritsumeikan Daigaku

Osamu Takahashi

Sei Roka Kokusai Daigaku

Research article

Keywords: Type 2 diabetes mellitus screening, A1c measurement, Cost effectiveness analysis

Posted Date: January 12th, 2021

DOI: https://doi.org/10.21203/rs.3.rs-51647/v2

License: (1) (i) This work is licensed under a Creative Commons Attribution 4.0 International License.

Read Full License 


\section{Abstract}

Background: To determine the best HbA1c test interval strategy for detecting new type 2 diabetes mellitus (T2DM) cases in a healthy population, $\mathrm{HbA} 1 \mathrm{c}$ test characteristics, risk stratification towards T2DM and cost effectiveness were considered.

Methods: State transition models were built to study the optimal screening interval for new cases of T2DM among each age- and BMI-stratified health population. Age was stratified into 30-44-, 45-59-, and 60-74-year-old age groups, and BMI was also stratified into underweight $\left(<18.5 \mathrm{~kg} / \mathrm{m}^{2}\right)$, normal $(18.5-25$ $\left.\mathrm{kg} / \mathrm{m}^{2}\right)$, overweight $\left(25-30 \mathrm{~kg} / \mathrm{m}^{2}\right)$ and obesity $\left(\geq 30 \mathrm{~kg} / \mathrm{m}^{2}\right)$. In each model, different HbA1c test intervals were compared to evaluate costs per quality-adjusted life year (QALY) and the incremental costeffectiveness ratio (ICER). We compared intervals annually (current Japanese strategy), every three years (US and UK recommendations) and tailored to each risk stratification group, based on our previous work. All model parameters, including screening and treatment costs, complications and mortality rates and utilities, were applied from published studies. The willingness-to-pay threshold in the cost-effectiveness analysis was set to US $\$ 50,000 /$ QALY.

Results: The HbA1c test interval for detecting T2DM in a healthy population varies by age and BMI. Three-year intervals were the most cost effective in obesity at all ages-30-44: \$15,034/QALY, 45-59: \$11,849/QALY, 60-74: \$8,685/QALY-compared with the other two interval strategies. The three-year interval was also the most cost effective in the 60-74-year-old age groups-underweight: \$11,377/QALY, normal: \$18,123/QALY, overweight: \$12,537/QALY-and in the overweight 45-59-year-old group; $\$ 18,918 /$ QALY. In other groups, the screening interval for detecting T2DM was found to be longer than three years, as previously reported. Annual screenings were dominated in many groups with low BMI and in younger age groups. Based on the probability distribution of the ICER, QALY does not show much difference among any groups.

Conclusions: Annual screening to detect T2DM was not cost effective and should not apply to any population. The three-year screening interval was optimal among all elderly populations, the obesity at all ages and the overweight 45-59-year-old group. For the low BMI and younger age groups, the optimal $\mathrm{HbA1c}$ test interval can be longer than three years.

\section{Background}

The number of patients with type 2 diabetes (T2DM) is expected to be close to 600 million worldwide by 2030. The HbA1c test to detect new cases of T2DM in a healthy population is one of the most effective ways to prevent and start early treatment for type 2 diabetes; however, the best frequency for $\mathrm{HbA} 1 \mathrm{c}$ testing remains unclear. Although multiple studies have tried to investigate the optimal frequency for $\mathrm{HbA} 1 \mathrm{c}$ testing, current guidelines about test frequencies to screen type 2 diabetes patients in a healthy population still rely on expert opinion. 
Kahn et al. [1] suggested that 30- to 45-year-old people are required to have 3- to 5-year interval screening on the basis of cost effectiveness analysis. However, this study does not consider the possibility of an incidence rate for type 2 diabetes based on risk factors. Multiple studies have reported that subjects with obesity are more likely to have type 2 diabetes than people with a normal BMI [2-4]. In addition to body mass index level, age also matters in the development of type 2 diabetes. The prevalence of type 2 diabetes increases as people live longer, and the complication rate among older adults with type 2 diabetes is significantly higher for both acute and chronic microvascular and cardiovascular diseases than that among younger adults with type 2 diabetes. People with a higher risk of onset of type 2 diabetes seem to require screening at shorter intervals than those with a lower risk [5, 6]. Previously, we reported and recommended that subjects with obesity aged 30-44 should be screened every 2 years, while those with a normal body mass index in the same age group would not need screening for the next 10 years because the paces of HbA1c progression are different based on age and BMI [6]. These results considered only $\mathrm{HbA} 1 \mathrm{c}$ test characteristics and did not include economic impact in determining the optimal interval for $\mathrm{HbA} 1 \mathrm{c}$ screening. People whose screening results were false positive may receive unnecessary treatment, and people whose screening results were false negative may incur higher treatment costs. When optimal screening intervals are introduced based on patient risk stratification, it would be possible to eliminate unnecessary tests as well as to minimize the chance of failing to detect affected patients.

Our study aimed to determine the optimal HbA1c test interval strategy to detect new type 2 diabetes mellitus (T2DM) cases in a healthy population stratified by age and body mass index (BMI), considering $\mathrm{HbA1c}$ test characteristics and cost effectiveness.

\section{Methods}

We built a state transition model of screening results and type 2 diabetes disease progression to simulate lifetime diabetes-related health care costs and QALYs. Our target population comprised individuals who had no history of T2DM or cardiovascular events. We stratified the population into age categories of 30-44, 45-59 and 60-74 years old. For each age category, we also stratified patients into BMI status as follows: underweight, $\mathrm{BMI}<18.5$; normal weight, BMI 18.6-24.9; overweight, BMI 25-29.9; and obesity, $\mathrm{BMI} \geq 30[7,8]$. In total, 12 stratifications were used to create the state transition models. We used the same tree structure for all 12 models with different parameter values. The tree structures in the state transition model comprise three main branches (Figure 1), "screening results by HbA1c test", "no screening year" and "T2DM progression". Screening result branches consist of parameters: incidence of T2DM and sensitivity and specificity of $\mathrm{HbA} 1 \mathrm{c}$ testing to determine how many individuals from the population go to the T2DM progression branch. In the no screening year branch, people are classified as the condition that was determined in the screening results branch. For example, if a person was categorized as false negative, they had a higher complication rate while they were in the no screening year because they technically missed a chance for early detection and treatment. In the T2DM progression branch, people die or may experience complications based on each relative risk. A first-order Monte Carlo simulation (microsimulation) of a hypothetical cohort of 50,000 people was performed to 
estimate the lifetime expected costs and expected QALY. The cycle length of the model was set to 1 year. A willingness-to-pay (WTP) threshold of 50,000 USD per QALY gained was used as the acceptable level for ICER. An annual discount rate of $2 \%$ was applied to both cost and benefit [9]. The incremental costeffectiveness ratio (ICER) was estimated as an indicator of cost effectiveness using the following formula: ICER = $\left(\right.$ Cost $_{\text {interval_a }}-$ Cost $\left._{\text {interval_b }}\right) /\left(Q A L Y d_{\text {interval_a }}-\right.$ QALY interval_b $)$. The model was developed and analyzed using TreeAge Pro 2016 (TreeAge Software, Williamstown, MA, USA).

\section{Parameters in the state transition models}

\section{Screening results by $\mathrm{HbA1c}$ test}

The sensitivity and specificity of the $\mathrm{HbA1c}$ test were calculated in each population using real data from St. Luke's International Hospital, Tokyo. We used the same data set and methodology to calculate sensitivity and specificity when we recommended different intervals based on risk stratification [6] (Table 2). The methodology has been described in detail elsewhere [10,11]. Briefly, linear random effect models with random intercept and random slope, adjusted for sex, age and BMI at first measurement of $\mathrm{HbA} 1 \mathrm{C}$ as continuous value, were used to generate predicted $\mathrm{HbA} 1 \mathrm{c}$. Sensitivity and specificity were calculated by comparing the observed $\mathrm{HbA} 1 \mathrm{c}$ value and the generated predicted $\mathrm{HbA} 1 \mathrm{c}$ value as the gold standard. 
Table 2

Sensitivity and specificity rates applied to the state transition models.

\begin{tabular}{|c|c|c|c|c|}
\hline $\begin{array}{l}\text { Age } \\
\text { category }\end{array}$ & BMI level & Interval & $\begin{array}{l}\text { HbA1c sensitivity } \\
(\%)\end{array}$ & $\begin{array}{l}\text { HbA1c specificity } \\
\text { (\%) }\end{array}$ \\
\hline \multirow[t]{12}{*}{$30-44$} & \multirow{3}{*}{$\begin{array}{l}\text { Underweight (< } \\
18.5 \mathrm{~kg} / \mathrm{m} 2)\end{array}$} & Annual & $\fallingdotseq 0.0$ & 100.0 \\
\hline & & 3 years & 50.0 & 100.0 \\
\hline & & 10 years & 81.8 & 99.9 \\
\hline & \multirow{3}{*}{$\begin{array}{l}\text { Normal } \\
(18.5-25 \mathrm{~kg} / \mathrm{m} 2)\end{array}$} & Annual & $\fallingdotseq 0.0$ & 100.0 \\
\hline & & 3 years & 47.5 & 99.9 \\
\hline & & 6 years & 68.1 & 99.9 \\
\hline & \multirow{3}{*}{$\begin{array}{l}\text { Overweight } \\
(25-30 \mathrm{~kg} / \mathrm{m} 2)\end{array}$} & Annual & $\fallingdotseq 0.0$ & 100.0 \\
\hline & & 3 years & 54.5 & 99.7 \\
\hline & & 4 years & 57.8 & 99.6 \\
\hline & \multirow{3}{*}{$\begin{array}{l}\text { Obese } \\
(\geq 30 \mathrm{~kg} / \mathrm{m} 2)\end{array}$} & Annual & $\fallingdotseq 0.0$ & 100.0 \\
\hline & & 2 years & 37.5 & 99.1 \\
\hline & & 3 years & 62.2 & 98.6 \\
\hline \multirow[t]{12}{*}{$45-59$} & \multirow{3}{*}{$\begin{array}{l}\text { Underweight (< } \\
18.5 \mathrm{~kg} / \mathrm{m} 2)\end{array}$} & Annual & $\fallingdotseq 0.0$ & 100.0 \\
\hline & & 3 years & 66.7 & 99.8 \\
\hline & & 10 years & 70.0 & 99.7 \\
\hline & \multirow{3}{*}{$\begin{array}{l}\text { Normal } \\
(18.5-25 \mathrm{~kg} / \mathrm{m} 2)\end{array}$} & Annual & $\fallingdotseq 0.0$ & 100.0 \\
\hline & & 3 years & 56.0 & 99.7 \\
\hline & & 6 years & 73.5 & 99.5 \\
\hline & \multirow{3}{*}{$\begin{array}{l}\text { Overweight } \\
(25-30 \mathrm{~kg} / \mathrm{m} 2)\end{array}$} & Annual & 2.5 & 100.0 \\
\hline & & 3 years & 61.1 & 99.1 \\
\hline & & 4 years & 66.8 & 99.0 \\
\hline & \multirow{3}{*}{$\begin{array}{l}\text { Obese } \\
(\geq 30 \mathrm{~kg} / \mathrm{m} 2)\end{array}$} & Annual & $\fallingdotseq 0.0$ & 100.0 \\
\hline & & 3 years & 62.0 & 98.0 \\
\hline & & 4 years & 71.4 & 98.0 \\
\hline \multirow[t]{2}{*}{$60-74$} & \multirow{2}{*}{$\begin{array}{l}\text { Underweight (< } \\
18.5 \mathrm{~kg} / \mathrm{m} 2)\end{array}$} & Annual & $\fallingdotseq 0.0$ & 100.0 \\
\hline & & 3 years & 50.0 & 99.5 \\
\hline
\end{tabular}




\begin{tabular}{|c|c|c|c|c|}
\hline $\begin{array}{l}\text { Age } \\
\text { category }\end{array}$ & BMI level & Interval & $\begin{array}{l}\text { HbA1c sensitivity } \\
\text { (\%) }\end{array}$ & $\begin{array}{l}\text { HbA1c specificity } \\
\text { (\%) }\end{array}$ \\
\hline & & 6 years & 87.5 & 99.3 \\
\hline & \multirow{3}{*}{$\begin{array}{l}\text { Normal } \\
(18.5-25 \text { kg/m2) }\end{array}$} & Annual & $\fallingdotseq 0.0$ & 100.0 \\
\hline & & 3 years & 50.3 & 99.3 \\
\hline & & 7 years & 72.7 & 99.1 \\
\hline & \multirow{3}{*}{$\begin{array}{l}\text { Overweight } \\
(25-30 \mathrm{~kg} / \mathrm{m} 2)\end{array}$} & Annual & $\fallingdotseq 0.0$ & 100.0 \\
\hline & & 3 years & 52.3 & 99.1 \\
\hline & & 5 years & 64.5 & 98.7 \\
\hline & \multirow{3}{*}{$\begin{array}{l}\text { Obese } \\
(\geq 30 \mathrm{~kg} / \mathrm{m} 2)\end{array}$} & Annual & $\fallingdotseq 0.0$ & 100.0 \\
\hline & & 3 years & 60.0 & 97.5 \\
\hline & & 4 years & 70.0 & 97.5 \\
\hline
\end{tabular}

\section{Cost}

Direct costs estimated in this study include screening cost and type 2 diabetes treatment. Indirect costs were not considered in this study. We estimated the unit costs of screening with the HbA1c test (including consumables, staff time and laboratory processing costs) as USD 80.00. We had to assume the fee for type 2 diabetes screening with $\mathrm{HbA} 1 \mathrm{c}$ because medical cost for prevention is not covered in Japan; thus, there was no official price list for the type 2 diabetes screening test in Japan. We estimated it by summing the cost for a T2DM patient with a stable glycemic condition who received a routine HbA1c test followed by a doctor's consultation.

For the treatment fee, we used published cost data for T2DM. Fukuda et al. [12] reported detailed treatment costs for T2DM as well as proportion rates for each T2DM-related complication. In our model, we aggregated to one treatment cost for any complication based on the proportions of Japanese people experiencing complications. We also estimated annual treatment fees for false positive patients by summing nutrition education and physical exercise education and assuming no drug prescription fees.

\section{Utility}

We assumed the utility value to be that of full health and set at 1 . We assigned 0.785 utility for those with T2DM without any complications based on a previous study [13]. We calculated a single utility value for those with T2DM with any complication based on multiple studies. Fukuda et al. [12] thoroughly reported treatment costs for patients with T2DM and the proportion of T2DM-

related complications using the Japan Medical Data Center Claims Database. We first retrieved utility values for each T2DM-related complication from previous studies and then weighted each utility value 
based on the proportion reported to aggregate into one utility, which represents the average utility value for patients with T2DM with any complication (Table 1).

Table 1

Parameters used in the tree model

\begin{tabular}{|c|c|c|c|c|c|}
\hline & Items & $\begin{array}{l}\text { Type of } \\
\text { distribution } \\
\text { of PSA }\end{array}$ & $\begin{array}{l}\text { Point } \\
\text { estimate }\end{array}$ & $\begin{array}{l}\text { Distribution } \\
\text { parameters } \\
\text { for PSA }\end{array}$ & $\operatorname{Ret}$ \\
\hline \multirow{9}{*}{$\begin{array}{l}\text { Cost } \\
\text { (USD) }\end{array}$} & \multirow[t]{2}{*}{ Screening cost } & \multirow[t]{2}{*}{ Gamma } & \multirow[t]{2}{*}{100} & $a=27.3$ & \\
\hline & & & & $\lambda=1 / 292$ & \\
\hline & \multirow{2}{*}{$\begin{array}{l}\text { Annual treatment fee among T2DM } \\
\text { patients without complication }\end{array}$} & \multirow[t]{2}{*}{ Gamma } & \multirow[t]{2}{*}{3,500} & $a=84146$ & \multirow[t]{2}{*}{ 12) } \\
\hline & & & & $\lambda=1 / 3$ & \\
\hline & \multirow{2}{*}{$\begin{array}{l}\text { Annual treatment fee among T2DM } \\
\text { patients with complication }\end{array}$} & \multirow[t]{2}{*}{ Gamma } & \multirow[t]{2}{*}{8,000} & $a=26540$ & \multirow[t]{2}{*}{ 12) } \\
\hline & & & & $\lambda=1 / 22$ & \\
\hline & \multirow{2}{*}{$\begin{array}{l}\text { Annual treatment fee among false } \\
\text { positive patients with no medication }\end{array}$} & \multirow[t]{2}{*}{ Gamma } & \multirow[t]{2}{*}{1,400} & $a=1752$ & \multirow[t]{2}{*}{ 12) } \\
\hline & & & & $\lambda=1 / 60$ & \\
\hline & Discount rate & - & 0.02 & - & 23) \\
\hline \multirow[t]{3}{*}{ Utility } & Utility for healthy population & - & \multicolumn{2}{|l|}{1} & 13) \\
\hline & $\begin{array}{l}\text { Utility for T2DM patients without } \\
\text { complication }\end{array}$ & - & 0.785 & - & 13) \\
\hline & $\begin{array}{l}\text { Utility for T2DM patients with } \\
\text { complication }\end{array}$ & - & 0.638 & - & 13) \\
\hline \multirow[t]{9}{*}{ Risk } & $\begin{array}{l}\text { Mortality rate among healthy } \\
\text { population }\end{array}$ & Life Table & - & - & \\
\hline & \multirow[t]{2}{*}{$\begin{array}{l}\text { Relative risk towards mortality rate } \\
\text { among T2DM patients with } \\
\text { complications }\end{array}$} & \multirow[t]{2}{*}{ LogNormal } & \multirow[t]{2}{*}{5.61} & $\begin{array}{l}\log (\text { mean })= \\
1.65,\end{array}$ & \multirow[t]{2}{*}{ 16) } \\
\hline & & & & $S E=0.08$ & \\
\hline & \multirow{2}{*}{$\begin{array}{l}\text { Relative risk towards mortality rate } \\
\text { among T2DM patients without } \\
\text { complications }\end{array}$} & \multirow[t]{2}{*}{ LogNormal } & \multirow[t]{2}{*}{2.61} & $\begin{array}{l}\log (\text { mean })= \\
0.95,\end{array}$ & \multirow[t]{2}{*}{16} \\
\hline & & & & $S E=0.14$ & \\
\hline & \multirow[t]{2}{*}{ Annual complication rate } & \multirow[t]{2}{*}{ Beta } & \multirow[t]{2}{*}{0.014} & $a=2.27$ & \multirow[t]{2}{*}{18} \\
\hline & & & & $\beta=160.3$ & \\
\hline & \multirow[t]{2}{*}{$\begin{array}{l}\text { Relative risk towards complication rate } \\
\text { among T2DM patients with treatment }\end{array}$} & \multirow[t]{2}{*}{ LogNormal } & \multirow[t]{2}{*}{0.79} & $\begin{array}{l}\log (\text { mean })= \\
-0.23\end{array}$ & \multirow[t]{2}{*}{19} \\
\hline & & & & $S E=0.09$ & \\
\hline
\end{tabular}


Table 4

Suggested screening strategies based on cost-effectiveness analysis, stratified by age and BMI group

\begin{tabular}{|lllll|}
\hline \multirow{4}{*}{ BMI group } & \multicolumn{4}{c|}{ Age groups } \\
\cline { 2 - 5 } & Underweight & 10-year & 10-year & 3-year \\
\cline { 2 - 5 } & Normal & 6-year & 6-year & 3-year \\
\cline { 2 - 5 } & Overweight & 4-year & 3-year & 3-year \\
\hline Obese & 3-year & 3-year & 3-year \\
\hline
\end{tabular}

\section{Risks from type 2 diabetes}

The age-dependent mortality rate for people without type 2 diabetes was obtained from the life table reported by the Ministry of Health, Labour, and Welfare in Japan [14]. We assumed that people with type 2 diabetes receiving the appropriate treatment would achieve the same mortality rate as people without type 2 diabetes based on a recent study [15]. The relative risks of mortality for patients with type 2 diabetes with and without complications were set to 5.22 and 2.61 , respectively $[16,17]$.

The annual incidence of T2DM complications was set to 0.014 based on a previous study [18]. Furthermore, we assumed that patients receiving appropriate treatment would experience fewer complications than those receiving no treatment. There are no published complication rate data for patients with no treatment; thus, we decided to retrieve data from the report, which compared metformin therapy versus conventional therapy. We treated conventional therapy as no treatment, so patients receiving appropriate treatment with metformin therapy had a 0.78-fold lower complication rate [19].

\section{Probabilistic sensitivity analysis (PSA)}

The robustness of the model results was explored by considering the impact of the model assumptions and the uncertainties in the model input parameters. This was done using deterministic and probabilistic sensitivity analyses (PSA), using the distribution for each parameter shown in Table 1. The PSA explored the uncertainties in the model parameters by randomly sampling 1,000 people with 1,000 iterations on each parameter distribution. We calculated the cost, QALYs and ICERs from this sample.

\section{Results}

Table 3 shows each QALY, incremental QALY, cost, incremental cost and ICER for 12 stratified groups based on age and BMI level. The HbA1c test interval to detect T2DM in a healthy population varies by age and BMI. Three-year intervals were the most cost effective in obesity at all ages -30-44: \$15,034/QALY, 45-59: \$11,849/QALY, 60-74: \$8,685/QALY-compared with the other two interval strategies. The threeyear interval was also the most cost effective in the 60-74-year-old groups-underweight: $\$ 11,377 /$ QALY, 
normal: \$18,123/QALY, overweight: \$12,537/QALY-and overweight in the 45-59-year-old group; dominant. In other groups, the screening interval for detecting T2DM was found to be longer than three years, as previously reported. Annual screenings dominated in many groups with low BMI and in younger age groups. Suggested screening strategies for all groups are shown in the Table 4. According to PSA, the results were consistent with the basic analysis (Appendix). Based on the probability distribution of ICER, the QALY does not show much difference among any groups.

Table 3. Results for the cost effectiveness analysis (first-order Monte Carlo simulation 50,000 times) 


\begin{tabular}{|c|c|c|c|c|c|c|c|}
\hline \multicolumn{2}{|c|}{ Population } & \multirow[t]{2}{*}{ Interval } & \multirow[t]{2}{*}{ QALY } & \multirow{2}{*}{$\begin{array}{l}\text { Incremental } \\
\text { QALY }\end{array}$} & \multirow[t]{2}{*}{ Cost (\$) } & \multirow{2}{*}{$\begin{array}{l}\text { Incremental } \\
\text { cost }(\$)\end{array}$} & \multirow{2}{*}{$\begin{array}{l}\text { ICER } \\
\text { (\$/QALY) }\end{array}$} \\
\hline Age & BMI group & & & & & & \\
\hline \multirow{15}{*}{$\begin{array}{l}30- \\
44\end{array}$} & \multirow[t]{4}{*}{ Underweight } & Annual & 30.12 & - & $2,467.16$ & - & Dominated \\
\hline & & 3-year & 30.16 & 0.01 & 963.10 & 557.19 & $93,898.79$ \\
\hline & & & & & & & $\begin{array}{l}\text { (vs 10- } \\
\text { year) }\end{array}$ \\
\hline & & 10-year & 30.16 & - & 405.92 & - & - \\
\hline & \multirow[t]{4}{*}{ Normal } & Annual & 30.13 & - & $2,489.28$ & - & Dominated \\
\hline & & 3-year & 30.15 & 0.01 & $1,112.80$ & 385.93 & $63,295.18$ \\
\hline & & & & & & & (vs 6-year) \\
\hline & & 6-year & 30.14 & - & 726.86 & - & - \\
\hline & \multirow[t]{3}{*}{ Overweight } & Annual & 29.86 & - & $2,894.63$ & - & Dominated \\
\hline & & 3-year & 29.97 & - & $2,678.14$ & - & Dominated \\
\hline & & 4-year & 29.97 & - & $2,477.31$ & - & Dominant \\
\hline & \multirow[t]{4}{*}{ Obese } & Annual & 28.88 & - & $4,313.80$ & - & - \\
\hline & & 2-year & 29.18 & - & $8,965.05$ & - & Dominated \\
\hline & & 3-year & 29.19 & 0.31 & $8,948.87$ & $4,635.07$ & $15,034.02$ \\
\hline & & & & & & & $\begin{array}{l}\text { (vs } \\
\text { Annual) }\end{array}$ \\
\hline \multirow{11}{*}{$\begin{array}{l}45- \\
59\end{array}$} & \multirow[t]{3}{*}{ Underweight } & Annual & 23.54 & - & $1,949.99$ & - & Dominated \\
\hline & & 3-year & 23.55 & - & 879.01 & - & Dominated \\
\hline & & 10-year & 23.55 & - & 408.86 & - & Dominant \\
\hline & \multirow[t]{3}{*}{ Normal } & Annual & 23.45 & - & $2,081.91$ & - & Dominated \\
\hline & & 3-year & 23.48 & - & $1,445.89$ & - & Dominated \\
\hline & & 6-year & 23.49 & - & $1,107.16$ & - & Dominant \\
\hline & \multirow[t]{3}{*}{ Overweight } & Annual & 23.17 & - & $2,763.11$ & - & Dominated \\
\hline & & 3-year & 23.20 & - & $2,753.06$ & - & Dominated \\
\hline & & 4-year & 23.26 & - & $2,908.66$ & - & - \\
\hline & \multirow[t]{2}{*}{ Obese } & Annual & 22.27 & - & $3,024.01$ & - & - \\
\hline & & 3-year & 22.66 & 0.4 & $7,647.58$ & $4,623.57$ & $11,849.71$ \\
\hline
\end{tabular}




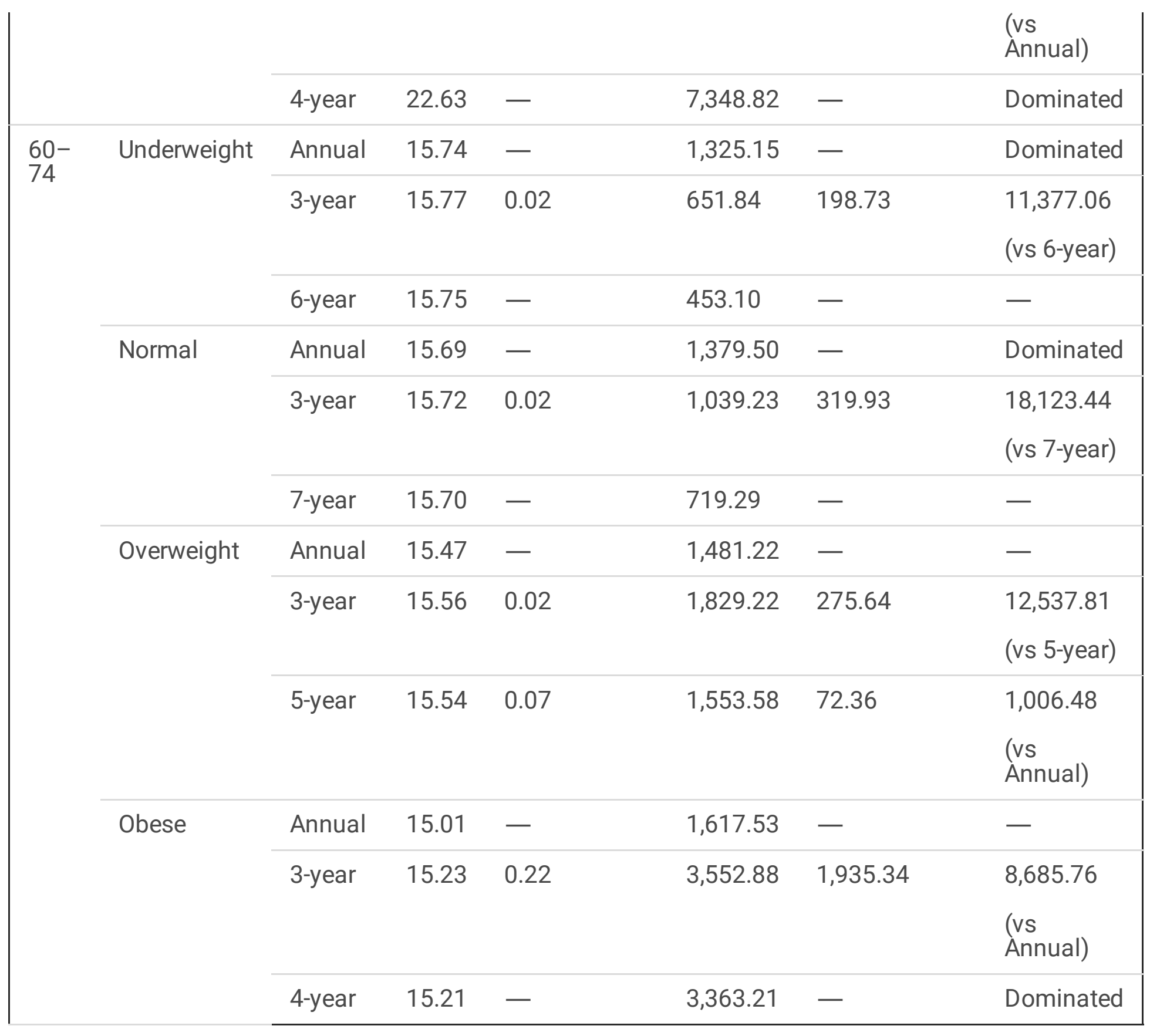

Underlined intervals are found to be the most cost-effective strategies with willingness-to-pay threshold of $\$ 50,000$. Units of costs, incremental costs and ICER is in USD\$.

\section{Discussion}

According to our cost-effectiveness analysis results, T2DM screening programs for healthy populations should consider risk stratification for T2DM. The optimal interval seems to vary from 3 to 10 years, and some groups do not require the 3-year screening interval that current guidelines suggest. There were no groups that warrant annual screening, which is required by Japanese law.

As we reported previously, $\mathrm{HbA1c}$ progression in the high-risk group was remarkable, while $\mathrm{HbA} 1 \mathrm{c}$ stayed at the same level or plateaued in the low-risk group. HbA1c progression in the lower risk 
group in the short interval is often affected by noise, which is originally possessed by HbA1c [6]. When deciding the appropriate screening testing frequencies, we should consider how well a screening program can distinguish true type 2 diabetes patients from true nondiabetic patients with the lowest financial burden to public health. To achieve this, health policies need to simultaneously integrate all influences according to patients' risk factors, $\mathrm{HbA} 1 \mathrm{c}$ test characteristics and financial impact.

Annual intervals dominated for all age groups of underweight and normal BMI individuals and the 30-44year-old overweight group. In other groups, annual intervals did not dominated; however, annual intervals were not warranted based on the ICER.

A 3-5 year monitoring interval suggested by Kahn et al. [1] while providing good evidence for cost effectiveness, does not apply to those over 45 years old. Chen et al. [20] concluded that a 5-year interval for all age groups would be the most cost-effective strategy. Interestingly, Hoerger et al. [21] concluded that the most cost-effective strategy is targeted screening of 55- to 75-year-old patients with hypertension. Moreover, Brateanu et al. [5] suggested that the optimal interval for type 2 diabetes screening should be decided by patients' risk score regarding the cause of type 2 diabetes; they concluded that patients in the highest risk group could be rescreened after 8 months, while those in the intermediate and lowest risk categories could be rescreened between 3 and 5 years. Our study also supports that risk stratification should be considered when deciding the optimal interval for type 2 diabetes. To the best of our knowledge, this study is the first to investigate the best interval for T2DM screening, considering both test characteristics and cost effectiveness. We have previously suggested optimal $\mathrm{HbA} 1 \mathrm{c}$ test screening results based on risk stratification of patients and test characteristics of the $\mathrm{HbA} 1 \mathrm{c}$ test. This time, we found that the results could change when we integrated economic evaluation as well as patient risk stratification and $\mathrm{HbA} 1 \mathrm{c}$ test characteristics. Patient risk stratification, $\mathrm{HbA1c}$ test characteristics and economic impact on public health not only should be used as the basis of health policy but also should be integrated and evaluated to maximize the effectiveness of mass screening.

As in many other studies, this study also includes uncertainties in our models. All patients will receive treatment once the screening test results are positive. We estimated that patients with T2DM will live if appropriate treatment is provided based on a previous report. In the real world, there should be a certain number of patients who do not visit clinics for treatment even after they receive positive results by screening tests. We estimated a lower complication rate if patients received treatment (true positive) and a higher complication and mortality rate if patients did not receive treatment (false negative). It was impossible to obtain published data for patients who did not receive treatment; thus, we had to retrieve data from the report comparing new treatment regimens versus conventional treatment regimens [19]. The intention of our study is not to identify the best risk stratification strategy. We stratified patients by age and current BMI level; however, there is room for consideration that BMI level in childhood should be applied instead of current BMI level, which has been reported to be more important for predicting the cause of new type 2 diabetes in adulthood [22]. We also did not consider due to data 
inaccessibility data for family history and patient medical history such as presence of prediabetes, hyperlipidemia and hypertension, which could be the candidate factors for robust stratification.

\section{Conclusions}

Annual screening to detect T2DM was not cost effective and should not be used for any population. The three-year screening interval was optimal for all elderly populations, the obesity at all ages and the overweight 45-59-year-old group. Among low BMI and younger age groups, the optimal HbA1c test interval can be longer than three years.

\section{List Of Abbreviations}

BMI: body mass index; T2DM: type 2 diabetes mellitus; HbA1c: hemoglobin A1c.

\section{Declarations}

\section{Ethics approval and consent to participate}

Ethical approval was obtained from the committees: the Research Ethics Committee of St. Luke's International Hospital, Tokyo, Japan, where exempted from obtaining written individual informed consent (approval code:15-R044).

\section{Consent for publication}

Not applicable

\section{Availability of data and materials}

Not applicable

\section{Competing interests}

All authors declare no competing interests.

\section{Funding}

This work was supported by the Ministry of Education, Culture, Sports, Science and Technology (MEXT), Grant-in-Aid for Young Scientists. Grant Number 26860429.

The grant agency was not involved in data collection, analysis, or interpretation; trial design; patient recruitment; or any aspect pertinent to the study. 


\section{Authors' contributions}

SO and OT designed the study and obtained data. SO and KM analyzed the data. SO, OT, and RP interpreted the data. OT, RP, and KM provided clinical and statistical advice. SO wrote the first draft.

All authors revised the manuscript and approved the final version prior to submission.

\section{Acknowledgements}

The authors acknowledge Professor Rafael Perera at the Nuffield Department of Primary Care Health Sciences, University of Oxford, Oxford, UK Professors Katy Bell and Kirsten Howard at School of Public Health, The University of Sydney, Sydney, Australia for their professional advice on our study.

\section{Authors' information}

1 Graduate School of Public Health, Clinical Epidemiology and HTA Center St. Luke's International University, 3-6-2 Akashi-cho, Chuo, Tokyo 104-0044, Japan. 2Department of General Internal Medicine, St. Luke's International Hospital, 9-1 Akashi-cho, Tokyo 104-8560, Japan. Ristumeikan University address will be followed.

\section{References}

1. Kahn R, Alperin P, Eddy D, Borch-Johnsen K, Buse J, Feigelman J, Gregg E,Holman RR, Kirkman MS, Stern M, Tuomilehto J, Wareham NJ. Age at initiation and frequency of screening to detect type 2 diabetes: a cost-effectiveness analysis. Lancet. 2010;375(9723):1365-74.

2. Hu FB, Manson JE, Stampfer MJ, Colditz G, Liu S, Solomon CG, et al. Diet, lifestyle, and the risk of type 2 diabetes mellitus in women. N Engl J Med. 2001;345:790-7.

3. Scanlon PH, Aldington SJ, Leal J, Luengo-Fernandez R, Oke J, Sivaprasad S, et al. Development of a cost-effectiveness model for optimisation of the screening interval in diabetic retinopathy screening. Health Technol Assess. 2015;19:1-116.

4. Mokdad AH, Ford ES, Bowman BA, Dietz WH, Vinicor F, Bales VS, et al. Prevalence of obesity, diabetes, and obesity-related health risk factors, 2001. JAMA. 2003;289:76-9.

5. Brateanu A, Barwacz T, Kou L, Wang S, Misra-Hebert AD, Hu B, et al. Determining the optimal screening interval for type 2 diabetes mellitus using a risk prediction model. PLoS One. 2017; 12:e0187695.

6. Ohde S, McFadden E, Deshpande GA, Yokomichi H, Takahashi O, Fukui T, et al. Diabetes screening intervals based on risk stratification. BMC Endocr Disord. 2016;16:65.

7. WHO Expert Consultation. Appropriate body-mass index for Asian populations and its implications for policy and intervention strategies. Lancet. 2004;363:157-63. 
8. Kanazawa M, Yoshiike N, Osaka T, Numba Y, Zimmet P, Inoue S. Criteria and classification of obesity in Japan and Asia-Oceania. World Rev Nutr Diet. 2005;94:1-12.

9. Fukuda T, Shiroiwa T, Ikeda S, Igarashi A, Akazawa M, Ishida H, et al. Guideline for economic evaluation of healthcare technologies in Japan. J Natl Inst Public Health. 2013;62:625-40.

10. Stevens RJ, Oke J, Perera R. Statistical models for the control phase of clinical monitoring. Stat Methods Med Res. 2010;19:394-414.

11. Perera R, McFadden E, McLellan J, Lung T, Clarke P, Pérez T, et al. Optimal strategies for monitoring lipid levels in patients at risk or with cardiovascular disease: a systematic review with statistical and cost-effectiveness modelling. Health Technol Assess. 2015;19:1-402.

12. Fukuda $H$, Ikeda S, Shiroiwa T, Fukuda T. The effects of diagnostic definitions in claims data on healthcare cost estimates: evidence from a large-scale panel data analysis of diabetes care in Japan. PharmacoEconomics. 2016;34:1005-14.

13. Beaudet A, Clegg J, Thuresson P-O, Lloyd A, McEwan P. Review of utility values for economic modeling in type 2 diabetes. Value Health. 2014;17:462-70.

14. Japan Ministry of Health, Labour, and Welfare. Life table for Japanese. Tokyo, Japan: Japan Ministry of Health, Labour, and Welfare; 2010.

15. Rawshani A, Rawshani A, Franzén S, Sattar N, Eliasson B, Svensson A-M, et al. Risk factors, mortality, and cardiovascular outcomes in patients with type 2 diabetes. N Engl J Med. 2018;379:633-44.

16. Preis SR, Hwang SJ, Coady S, Pencina MJ, D'Agostino RB, Savage PJ, et al. Trends in all-cause and cardiovascular disease mortality among women and men with and without diabetes mellitus in the framingham heart study, 1950 to 2005. Circulation. 2009;119:1728-35.

17. Cusick M, Meleth AD, Agron E, Fisher MR, Reed GF, Knatterud GL, et al. Associations of mortality and diabetes complications in patients with type 1 and type 2 diabetes: Early treatment diabetic retinopathy study report no. 27. Diabetes Care. 2005;28:617-25.

18. McAlpine RR, Morris AD, Emslie-Smith A, James P, Evans JMM. The annual incidence of diabetic complications in a population of patients with type 1 and type 2 diabetes. Diabet Med. 2005;22:34852.

19. Holman RR, Paul SK, Bethel MA, Matthews DR, Neil HAW. 10-year follow-up of intensive glucose control in type 2 diabetes. N Engl J Med. 2008;359:1577-89.

20. Chen THH, Yen MF, Tung TH. A computer simulation model for cost-effectiveness analysis of mass screening for type 2 diabetes mellitus. Diabetes Res Clin Pract. 2001;54:37-42.

21. Hoerger TJ, Harris R, Hicks KA, Donahue K, Sorensen S, Engelgau M. Screening for type 2 diabetes mellitus: a cost-effectiveness analysis. Ann Intern Med. 2004;140:689-99.

22. Bjerregaard LG, Jensen BW, Ängquist L, Osler M, Sørensen TIA, Baker JL. Change in overweight from childhood to early adulthood and risk of type 2 diabetes. N Engl J Med. 2018;378:1302-12.

23. Shiroiwa T, Fukuda T, Ikeda S, Takura T, Moriwaki K. Development of an Official Guideline for the Economic Evaluation of Drugs/Medical Devices in Japan. Value Health. 2017 Mar;20(3):372-378. 
Figures

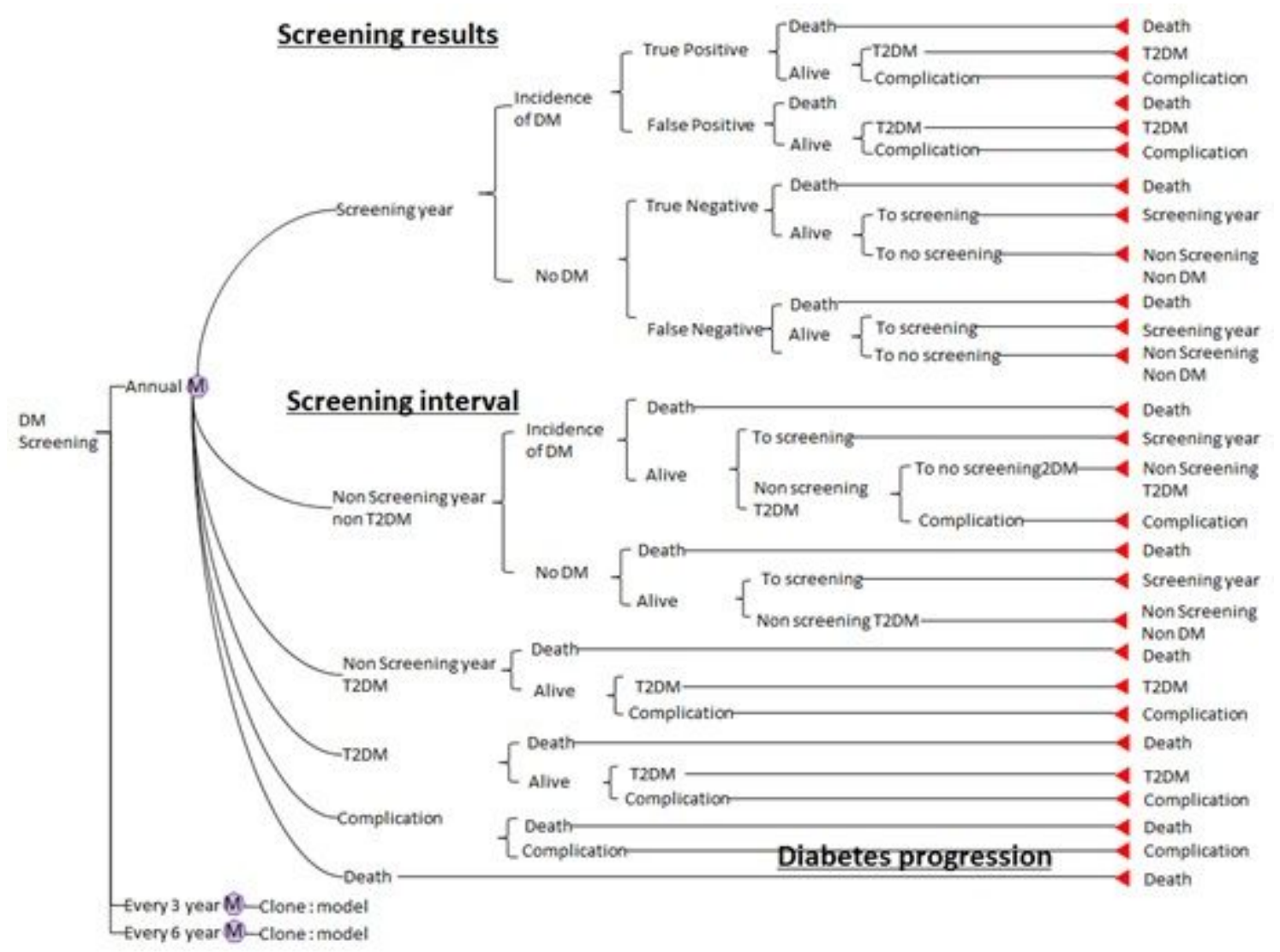

Figure 1

Tree models.

\section{Supplementary Files}

This is a list of supplementary files associated with this preprint. Click to download.

- appendix.docx 